\title{
Da história para a ficção: as relaçöes de gênero nos séculos XVI e XVII nas páginas de "Las dos doncellas", de Cervantes
}

\author{
From history to fiction: gender relations in the XVI and XVII centuries \\ in the pages of Las dos doncellas, by Cervantes
}

Edwirgens A. Ribeiro Lopes de Almeida Universidade Estadual de Montes Claros, Montes Claros, MG, Brasil

Resumo: Neste texto, discutimos a estratégia adotada pelo escritor espanhol Miguel de Cervantes para compor a representação feminina em Las dos doncellas, narrativa breve integrante do conjunto intitulado Novelas ejemplares. Com esse propósito, demonstramos como Cervantes se apropriou de alguns parâmetros descritos em tratados éticos, morais e religiosos do entorno do Século de Ouro para compor, num primeiro plano, a conduta adotada pelas mulheres da ficção e, por outro lado, de modo sutil, o escritor dá certa "liberdade" a essas criaturas, deixando-as transgredir algumas regras e evidenciando posturas distintas daquelas predominantes para as mulheres de seu tempo.

Palavras-chave: Cervantes. Mulheres. Tratados. História. Ficção.

Abstract: This article discusses the strategies adopted by Miguel de Cervantes in his representation of women in $L a$ dos doncellas, in Novelas ejemplares. By seizing some of the models that were constant in ethical, moral and religious treatises of the Spanish Golden Age, Cervantes seems at first sight to reproduce such patterns in his own female characters. However, Cervantes was not only reproducing these very conventional treatises, for he gave a certain degree of freedom to his female characters and presented them violating the traditional rules of the time.

Keywords: Cervantes. Women. Treatises. History. Fiction. 
Si las mujeres hubiesen escrito los libros, Estoy segura de que lo habrían hecho de otra forma,

Porque ellas saben que se las acusa en falso.

(Cristina de Pizán, 1399)

Estudar a representação de mulheres no princípio do século XVII requer um retorno ao percurso pelo qual as mulheres passaram ou no qual foram imaginadas e escritas por homens e por mulheres.

Edwirgens A.

Ribeiro Lopes

de Almeida

Como essa trajetória feminina, a nosso ver, é algo importante para se compreender a relação entre homens e mulheres, materializada nos relatos cervantinos, faz-se necessário averiguar como era a vida social das mulheres no Século de Ouro, para intentarmos analisar o quanto Cervantes procurou ser coerente com a sociedade que o rodeava. Esse escritor utilizou os seus registros para, além de revelar as experiências vividas, provocar reflexões acerca da paradigmática condição hierárquica social a que estiveram submetidos tanto mulheres quanto homens de seu entorno.

Se a maioria dos registros que permitiram o conhecimento dos embates sobre a caracterização, os papéis sociais, as características biológicas e psicológicas de homens e de mulheres desde a Antiguidade foram textos literários, é patente afirmar que a relação entre os textos literários e o discurso histórico nesse contexto do Século de Ouro é muito tênue. Relevantes historiadores e sociólogos, como Marcelin Defourneaux, Mariló Vigil, Ludwig Pfandl e José Antonio Maravall, recorrem a recortes da literatura para exemplificar a estratificação social, bem como os seus costumes. Nesse intento, Miguel de Cervantes e suas narrativas são referências citadas, constantemente, a fim de relatar as práticas predominantes do seu tempo.

Sendo assim, a nosso ver, para um estudo atento do texto cervantino, é imprescindível um diálogo com alguns tratados de conduta moral daquele tempo, já que o autor, assim como seus contemporâneos, foi fortemente influenciado pelas ideologias reinantes em seu contexto. Para isso, necessário se faz um olhar sobre as configurações de homem e de mulher que são ditadas por alguns moralistas e que vão, de certo modo, definir ou redefinir, pelo menos na ficção, as relações hierárquicas de poder entre os gêneros. Conforme assevera Mariló Vigil, "los moralistas españoles de aquella época expresaron en el plano ideológico, por una parte, la visión del mundo de las clases aristocráticas 
que defendían un orden social estamental, y por otra, actuaban como portavoces de un ideal masculino de sociedad, fuertemente patriarcal" (VIGIL, 1994, p. 15). A opinião da socióloga nos põe diante da parcialidade dos discursos emitidos pelos moralistas, que ora privilegiavam uma determinada classe social, ora o gênero masculino.

Para Mariló Vigil, a questão biológica do sexo, ou seja, do gênero se configura em um determinado argumento para outras formas de controle social. Citando Reissman, Vigil explica que as

\footnotetext{
diferencias biológicas, reales o supuestas, pueden ser utilizadas como base para la estratificación social; 'se invoca lo biológico como justificante para apoyar desigualdades sociales existentes, y si cambían las definiciones sociales referentes a la igualdad lo mismo ocurre con las justificaciones biológicas de que se hizo uso' (VIGIL, 1994, p. 15).
}

A par dessa questão, a moral eclesiástica do século XV defendia um modelo de estratificação social no qual as mulheres correspondiam às expectativas do homem, sendo boas mães, exemplares donas de casa e apoiadoras afetivas do marido, tudo sob o comando imediato masculino. A socióloga explica ainda que, nesse século, também se produziram fortes polêmicas entre quem atacavam e defendiam as mulheres, como podemos citar a atuação de Cristina de Pizán. Completa a autora: "el furor planfetario antifemenino que se desató puede indicar que las mujeres no se adaptaban a las pautas de comportamiento previstas para ellas por la ideología masculina emergente: una ideología destinada a mujeres urbanas o burguesas" (VIGIL, 1994, p. 16). De acordo com a informação de Mariló Vigil, novamente podemos explicar a coerência desta nossa leitura em relação à presença do discurso e das práticas predominantes das mulheres que povoam o cenário novelesco de Las dos doncellas. Salienta a historiadora as resistências oferecidas pelas mulheres, já que, teoricamente, os tratados se destinavam a determinadas classes de mulheres, mas, na prática, constituíam-se em exigências que se estendiam a todos os indivíduos do gênero feminino, em seus mais diversos estamentos sociais. Nesta leitura, podemos depreender, através de distintas estratégias, essa sutil resistência feminina que, paradoxalmente, pode ser entendida como uma aceitação. 


\section{Edwirgens A.}

Ribeiro Lopes

de Almeida

No combate travado entre mulheres e homens pela valorização do gênero, sobretudo feminino, os discursos misóginos influenciaram o modo de ver da mulher no século XVI, porém

\footnotetext{
la mayoría de los moralistas optaron por dejar de lanzar improperios misóginos y se dedicaron en gran medida a elaborar modelos de perfectas doncellas, perfectas casadas, perfectas viudas y perfectas monjas, para tratar de convencer a las mujeres de que se ajustaran a las normas de acción que correspondían a los papeles y estados en los que trataban de ser ubicadas por el poder masculino (VIGIL, 1994, p. 17).
}

É lícito destacar que os moralistas escreviam, entretanto, para mulheres urbanas de classes média e alta. Contudo, é fato também que esses eram os padrões que indicavam os modelos de comportamentos, que geravam imitação dos baixos estamentos. Conforme ainda Mariló Vigil, a divisão entre solteiras, casadas, viúvas e monjas é mais significativa que dividi-las em esposas ou filhas de nobres, letrados, comerciantes e outros, pois "las relaciones de poder a que están sometidas todas las mujeres se derivan, en primer lugar, de sus posiciones en la família. Ser prisioneras de lo doméstico es lo que une a todas ellas" (VIGIL, 1994, p. 17).

Um dos textos de mais envergadura acerca de modelos de comportamentos das mulheres era, assim como os demais tratados, assentado no discurso religioso, a obra de Juan Luis Vives Instrución de la mujer Cristiana. Escrita na segunda década do século XVI, essa obra foi um relevante manual moralizante da educação da mulher. Dedicada à rainha Catalina de Inglaterra, filha de Isabel, a católica, Instrucción de la mujer Cristiana se divide em três partes: a primeira trata da educação da mulher virgem, a segunda refere-se às mulheres casadas e a terceira parte orienta o modo de vida das viúvas. Toda a obra manifesta o interesse pedagógico, humanístico, moral e cristão especialmente em relação à instrução de meninas e de seus deveres como esposas.

Pela obra de Vives, deve-se tomar o maior cuidado com a criação e a educação da mulher, porque é ela a responsável pelo bem ou pelo mal da vida "entera".

Pues, ¡cuánto mayor cuidado debemos poner en la crianza y vida de la mujer cristiana; siendo tan importante al vivir humano, 
que todo el bien y mal que en el mundo se hace se puede sin yerro decir ser por causa de las mujeres según en el proceso de esta obra se podrá comprehender! (VIVES, 1995, p. 31).

O fragmento deixa claro o propósito de ensinamento que o texto pretende alcançar, ao mesmo tempo que enfatiza, pela expressão "sin yerro", a garantia das informações ali prestadas. Segundo Luiz Costa Lima (2007), pensando a partir de Edward Riley, os livros moralizantes, tendo em vista a garantia da moral religiosa, tornavam-se perturbadores da condução do indivíduo no cotidiano, uma vez que, como mostraremos posteriormente, nem sempre as práticas da vida social correspondiam àquelas prescritas pelas ordens religiosas.

O discurso, preocupado com a intervenção das práticas na ordem

Da história para a ficção social, é endossado pela ideia religiosa de que a mulher deve se assemelhar à Maria, mãe de Jesus, como a mulher honesta, passiva e acolhedora do marido e dos filhos e, para garantir essa condição, a virtude principal da mulher anotada por Vives é a castidade. Tratada como uma "joya", a virgindade ou a castidade feminina devia ser assegurada até o casamento. “¿Tú no habrás temor de echarte a perder para siempre y dar en el aire lo que no se puede dar por ningún precio? [...]”. E assevera que, frente à perda da virgindade de uma donzela, "Todo se le hará triste, lloroso, dolorido, lleno de espanto y de rabia contra sí misma. ¿Qué dolor es el de los padres? ¿Qué infamia de los parientes? ¿Qué tristeza de los amigos? ¿Qué gemidos de los familiares? ¿Qué lágrimas de los que la criaron?" (VIVES, 1995, p. 76).

Conforme vimos esclarecendo, o enredo bordado no tecido narrativo de Las dos doncellas revela, em primeiro plano, a conservação desses pressupostos. Uma leitura superficial da narrativa indica que essa concepção religiosa da mulher nela predomina. Nessa narrativa breve, ambas as moças são nobres, filhas de importantes famílias e educadas pelos dogmas católicos. A protagonista Teodosia entrega-se a Marco Antonio e, com a viagem dele, ela parte em busca do resgate de seu amor e de sua honra. A lamentação da protagonista na ficção pode ser lida como uma representação da argumentação de Vives:

- ¡Ay sin ventura! ¿Adónde me lleva la fuerza incontrastable de mis hados? [...] ¿Qué fin ha de tener esta no sabida peregrinación mía? ¡Ay honra menospreciada! jay amor mal agradecido! jay respectos de honrados 
padres y parientes atropellados! ¡y ay de mí una y mil veces, que tan a rienda suelta me dejé llevar de mis deseos! ¡Oh palabras fingidas, que tan de veras me obligastes a que obras os respondiese! Pero ¿de quien me quejo, cuitada? ¿Yo no soy la que quise engañarme? (CERVANTES, p. 147-148).

Como prevê Vives, a protagonista, sob suas lamentações, dimensiona a intensidade de suas perdas. Ela mesma exprime arrependimento Edwirgens A. e raiva de si mesma quando questiona a responsabilidade de seus atos, Ribeiro Lopes justificando a seu irmão que é a "amarga história de mis desgracias". de Almeida No excerto apresentado, Teodosia também está consciente da desonra e tristeza que tal ato desencadeará em sua família, o que a instiga a buscar uma forma de reparação do erro.

Para justificar o que ela chama de "principio de mi locura", isto é, a sua entrega a Marco Antonio, Teodosia explica a seu interlocutor, embora nesse momento ela não tenha conhecimento de que ele é seu irmão Don Rafael, que cada palavra de seu amado era como

un tiro de artillería que derribaba parte de la fortaleza de mi honra; cada lágrima era un fuego en que se abrasaba mi honestidad; cada suspiro, un furioso viento que el incendio aumentaba de tal suerte que acabó de consumir la virtud que hasta entonces no había sido tocada (CERVANTES, p. 151).

Expressões como "fortaleza de mi honra", "abrasaba mi honestidade" e "consumir la virtude" indicam que a personagem, educada dentro dos preceitos orientados pela religião, como bem constata o narrador, é conhecedora dos riscos e dos prejuízos que aquela condição poderia trazer a si mesma e a sua família. Como explica o historiador francês Marcelin Defourneaux,

a desonra tem por causa a infidelidade da mulher ou o insulto à virtude. Todo grupo familiar se sente desonrado e cada um não só o marido, mais o pai, o irmão, o tio - tem o direito de se vingar. Demais sendo a honra um valor absoluto e tendo sua fonte na opinião, uma suspeita, mesmo injustificada, pode importar em um castigo implacável (DEFOURNEAUX, 1983, p. 192). 
No caso da ficção, Don Rafael, irmão de Teodosia, sente-se autorizado a realizar, em nome da irmã e da sua família, “a venganza del agravio". Sendo assim, partem para as proximidades de Salamanca em busca de Marco Antonio. Comungando do discurso histórico, a obra de arte coloca em evidência a relevância da honra, endossada pelos discursos moralistas que, naquele contexto, são orientados pelas ideias religiosas. Segundo os postulados de Defourneaux, "os dois componentes primaciais da alma espanhola, a fé católica e o zelo da honra, combinam-se num valor comum: a honra de ser cristão" (DEFOURNEAUX, 1984, p. 47). Na narrativa objeto desta investigação, os valores decorrentes de serem as personagens cristãs são reiterados constantemente, sobretudo quando se destaca que, em virtude dessa religião, precisa-se garantir a sua honra. E o resgate dessa honra é o que encoraja as donzelas Leocadia e

Da história para a ficção Teodosia em suas ações. Sendo assim, a honra é vista pelos moralistas como o maior valor da mulher, aspecto que a assemelha à virgem Maria.

Vemos que o limite existente entre a religião e a honra é muito estreito, como explica o historiador. Esta última é objeto de muitas recomendações nos discursos moralistas porque seria facilmente destruída, como está posto no último trecho em destaque, isto é, uma simples suspeita consistiria num fator de desonra. Para evitar esse infortúnio, Juan Luis Vives argumenta que a mulher virgem, quando sai de casa, "pone en el peso de las lenguas a su hermosura, y su crianza, su saber, su bondad, comoquiera que no hay cosa hoy en el mundo tan tierna ni tan delicada ni tan frágil como es la honra y reputación de la mujer" (VIVES, 1995, p. 137). O olhar de Vives sobre as fragilidades do feminino remete-nos à presença da mulher ficcional construída dentro desse paradigma de delicadeza, passividade e fragilidade. Contudo, iremos mostrar a seguir que essa imagem pode ser vista como uma estratégia de dominação e conquista da mulher, o que resulta numa forma de reflexão do papel social dos gêneros proveniente do autor.

Voltando às correspondências percebidas entre a ficção e o discurso de teor moral, a fragilidade da mulher e de sua honra é ressaltada também no relato de La perfecta casada, de Fray Luis de León. Nesse manual de convenções para a mulher casada, Fray Luis destaca que,

siendo las mujeres de su cosecha gente de gran pundonor, apetitosas de ser apreciadas y honradas, como son todos los de ánimo flaco, y gustando de vencerse entre sí unas a otras, aun en cosas 
menudas y de niñería, no se precian, antes se descuidan y olvidan de lo que es su propia virtud y loa (LEÓN, 1953, p. 43-44).

Explicando sobre as duas qualidades principais que deve ter uma mulher casada, Juan Luis Vives assegura:

Entre las otras virtudes la mujer casada ha de tener dos principales. Las cuales solas pueden hacer que el matrimonio sea

Edwirgens A.

Ribeiro Lopes

de Almeida

206

firme, estable, perpetuo, fácil, ligero, dulce y lleno de felicidad; y faltándola una de ellas, enfermo, grave, odioso, intolerable, y lleno de amargura y miseria. Estas son castidad y afición entrañable a su marido. La primera se debe traer de casa del padre y la segunda tomarla entrando por las puertas del marido. (VIVES, 1995, p. 211).

Mais uma vez em texto do século XVI, a honra é entendida como uma virtude suprema da qual derivarão outras qualidades da mulher. Pelos escritos misóginos da Antiguidade, essa honra deve ser preservada da fragilidade e da vulnerabilidade da própria mulher.

Em suma, na narrativa Las dos doncellas, o leitor se vê defronte a situações do cotidiano que representavam a ordem instituída, o que confere intensa correspondência da história com a ficção e imprime considerável coerência ao desenvolvimento interno da obra. Com esse mecanismo na criação do sentimento de verdade do texto, o autor usa a história como um pretexto para partilhar com seu leitor a reflexão sobre o exercício de poder, o jogo de aparências e a hierarquia que coloca alguns seres em detrimento de outros, seja através do gênero, seja da classe social. A partir dessa premissa, é importante ter presentes os aspectos dos quais Cervantes fez uso para parecer às vezes conservador e, por outra leitura, às vezes subversivo. Porém, antes de fazer a nossa leitura sobre essa reflexão, isto é, sobre a revisão de alguns paradigmas e pressupostos em voga naqueles tempos, vale dar seguimento às anotações a respeito de como a apreciação do discurso moral acontece na ficção e como é colocada em primeiro plano de leitura.

Em Las dos doncellas, as posturas das personagens Teodosia e Leocádia, numa primeira dimensão, são bastante coerentes com as orientações de Vives, León, Guevara, Baltasar Gracián e outros autores anotados anteriormente. 
Contudo, a leitura dessa novela se torna um tanto mais problemática no que se refere à questão das identidades de gênero, uma vez que temos mulheres travestidas de homens, que, como parte do disfarce, trocam os seus nomes. O próprio narrador utiliza algumas estratégias para denominar Teodosia por Teodoro e Leocadia por Francisco, tendo em vista as suas conveniências. Nesse embate dos nomes na atuação das personagens, fica entrevista a problemática das identidades de gênero, ora o masculino, ora o feminino.

Para adentrar à instância textual, vale recordar que essa obra conta a história de duas moças, chamadas Teodosia e Leocadia, que decidem, cada uma a seu modo, vestir-se de homem com a finalidade de resgatar a honra ferida pelo cavalheiro Marco Antonio. Já anotamos anteriormente, a partir de Vives (1995) e Defourneaux (1983), que a honra

Da história para a ficção possuía um valor que se equipararia à vida naqueles tempos. A honra correspondia à guarda da castidade, da virgindade e de qualquer mácula na conduta da mulher. Segundo assevera Juan Luis Vives, a virgindade era o bem supremo da mulher. Para ele,

\footnotetext{
no hay quien no ponga los ojos en la virgen. ¡Cuán dulce!, ¡Cuán agradable!, ¡Cuán amada es la virgen! ¡Cuán aborrecida! ¡Cuán desechada!, ¡Cuán huída de todas partes es la corrupta! No sólo entre los cristianos, pero entre los gentiles era en muy gran estima la virgindad (VIVES, 1995, p. 73).
}

Vejamos com que intensidade o moralista destaca a relevância da virgindade e o valor da virgem, tratados em outro momento como uma joia. Como explica Mariló Vigil (1994), esse pensamento era comum entre os moralistas e a sociedade laica em geral. Sendo assim, Didier Souiller afirma que a "mulher era a responsável por preservar sua própria honra" (SOUILLER, 1985, p. 23). E é com o propósito de recuperar essa honra que as duas partem de suas casas em busca do homem escolhido como pretendente ao matrimônio.

Primeiramente, a obra nos apresenta Teodosia chegando em uma pousada, porém na condição de Teodoro. O que podemos notar é que a trama se torna complicada por se tratar de uma donzela, mas que está travestida de varão. Com um mecanismo de exposição dos gêneros, veremos que o narrador precisa se equilibrar ao atribuir-lhe características ora de homem, ora de mulher. Parecendo ser uma jovem 
de 16 ou 17 anos, logo é ressaltada a sua beleza, isto é, na condição de homem, "todos trataron de la grande hermosura y gallarda disposición del nuevo huésped, concluyendo que jamás tal beleza habían visto" (CERVANTES, p. 144).

Conforme salientamos anteriormente, o certo exagero na idealização da personagem nessa condição de homem parece exprimir uma irônica proposta de reflexão sobre os privilégios de linhagem, de gênero, ao mesmo tempo que expõe uma concordância com os preceitos de Edwirgens A. valorização da beleza, sobretudo da mulher. Jean Delumeau explica que Ribeiro Lopes o Renascimento foi um período em que mais se destacou a beleza física de Almeida da mulher. A respeito do comportamento e da beleza da mulher, Jean Delumeau alude ao livro de Castiglione, que menciona a Donna dipalazzo, expondo como deve ser uma dama: "cabe-lhe ser bela, doce, delicada e, naturalmente, graciosa. Cuidará da modéstia de conduta e da honestidade das palavras mais ainda que os homens; será discreta e bondosa. Não dará estímulo a maledicências nem calúnias" (DELUMEAU, 1984, p. 90). Ao mesmo tempo que ressalta a beleza e o bom comportamento, reprime certas ousadias da mulher, para que não se exponha à opinião e comentários públicos, já que, de todo modo, a beleza física estava relacionada ainda ao caráter.

Em seguida, o narrador nos mostra a beleza do outro hóspede, agora Don Rafael, irmão de Teodosia, dizendo estarem pousando “ángeles" naquele lugar. Ele ainda não sabia da presença da irmã disfarçada de Teodoro e queria conhecê-la, aliás, conhecê-lo. Tamanha é a beleza do moço que Don Rafael arquiteta um plano para conferir a informação recebida da funcionária da pousada e tenta hospedar-se no quarto somente com ele. A mentira aqui é uma estratégia para descortinar a identidade daquele estranho varão. No quarto, o quadro que se pinta demonstra a presença feminina regida de lamentações, choros e suspiros. Em suas lamentações, a personagem dizia a si mesma:

- ¡Ay sin ventura! ¿Adónde me lleva la fuerza incontrastable de mis hados? ¿Qué camino es el mío o qué salida espero tener del intrincado labirinto donde me hallo? ¡Ay pocos y mal experimentados anõs, incapaces de toda buena consideración y consejo! ¿Qué fin ha de tener esta no sabida peregrinación mía? ¡Ay honra menospreciada! [...] ¡Ay respectos de honrados padres y parientes atropellados! [...] ¿No soy yo la que tomó el cuchillo con sus mismas manos, con que corté y eché por 
tierra mi crédito, con el que de mi valor tenían mis ancianos padres? (CERVANTES, p. 147-148).

Vejamos que as palavras de Teodoro não são coerentes para a expressão de um homem dentro das expectativas predominantes daquele tempo. Embora vestida de homem, poucos são os momentos em que suas atitudes se aproximam daquelas previstas para os homens. 0 que predomina na representação dessa personagem são seus pensamentos, precauções e prevenções, inclusive o objetivo final é o de mulheres tradicionais, ou seja, o casamento. Aqui e em seus pensamentos, ela age como mulher, suas lamentações ratificam que, sob o olhar da mulher, ela precisa ser guiada.

O questionamento da personagem "no soy yo la que tomó el Da história para a ficção

cuchillo con sus mismas manos, con que corté y eché por tierra mi crédito, con el que de mi valor tenían mis ancianos padres?" tem muito a nos dizer quando nos remetemos ao olhar histórico sobre a situação das mulheres nas relações familiares e sociais. Como externa Castiglione no trecho citado por Delumeau (1984), a mulher precisa conter as suas ações e as suas palavras, e o próprio ato de travestir-se configura uma ruptura dessa disciplina. A lamentação da protagonista revela a sua culpa frente ao ato de desonra, demonstrando que, como reiteram os códigos, a mulher precisa ser conduzida pelo homem. Nesse ponto, Teodosia é bem cativa de sua posição.

Outro ponto importante da oração diz respeito à sua preocupação com a honra de seus pais. Como relatamos a partir de Didier Souiller (1985), era a mulher a responsável pela preservação da sua honra e, por conseguinte, da honra de toda a família, pois, como explicou Defourneaux, a honra se tornava uma preocupação coletiva, já que a sua perda acometia a todos de casa e podia ser cobrada por um membro desta. Segundo ele, "todo o grupo familiar se sente desonrado e cada um - não só o marido, mas o pai, o irmão, o tio - tem o direito igual de se vingar" (DEFOURNEAUX, 1983, p. 46). No mesmo fragmento exposto, Teodosia também se questiona acerca do seu destino, vinculando-o apenas à entrega ao homem amado. Enfim, ela dá continuidade às suas lamúrias demonstrando o sentimento nutrido por Marco Antonio, a delicadeza e a consequente fragilidade do seu ser mulher. 
¡Oh fementido Marco Antonio! ¿Cómo es posible que en las dulces palabras que me decías veniese mezclada la hiel de tus descortesías y desdenes? ¿Adónde, estás, ingrato? ¿Adónde te fuiste, desconocido? Respóndeme, que te hablo; espérame, que te sigo; susténtame, que descaezo; págame lo que me debes; socórreme, pues por tantas vías te tengo obligado. (CERVANTES, p. 148).

O pensamento exposto por Teosodia, embora esteja vestida de Edwirgens A. homem, é bastante coerente com o modo de ver da sociedade acerca da Ribeiro Lopes maioria das mulheres, já que eram preparadas para o casamento. Nessa de Almeida obra, embora contrastando com os disfarces de homem, temos mulheres muito românticas, sobretudo a protagonista Teodosia. Para ratificar as posturas femininas, Don Rafael chega à conclusão de que "sin duda alguna era mujer la que se quejaba" (CERVANTES, p. 148).

Como podemos perceber, em vários aspectos, o paradigma de homens e de mulheres se difere, e é isso que vamos mostrando neste estudo. Muitas vezes, as mulheres tiveram iniciativas que feriram esse prescrito para elas, ao mesmo tempo que os homens também agiram de modo diverso ao que está posto nos manuais. No plano histórico, sabemos que isso é recorrente, como pondera Mariló Vigil (1994), mas no plano literário, e tendo em vista a censura daquele tempo, é pertinente abordar as estratégias artísticas utilizadas a fim de "camuflar" certas subversões e transgressões de homens e de mulheres, já que uma das funções de textos naquele tempo era inclinar o ânimo dos leitores e, dessa forma, elogiar as virtudes. Para isso, a quebra das virtudes, isto é, as condutas consideradas vícios precisam de distintos tipos de textos que os censurassem e colocassem em primeiro plano as virtudes. Sendo assim, estrategicamente, Cervantes constrói dimensões de leitura em seus textos, revelando a dinâmica das relações sociais e de gênero, mas a interpretação fica a critério do leitor.

Interessante anotar que a protagonista exibe, em seus pensamentos, um exemplo ideal de mulher, aspecto que é contrastado em sua prática. Explica a Don Rafael que deveria ter "puesto más freno a mi lengua y más tregua a mis suspiros" (CERVANTES, p. 149). Aqui, ela reconhece a necessidade do recato outrora explicado pelos moralistas e, no trecho seguinte, revela a verdadeira identidade de mulher: "soy una desdichada doncella, a lo menos una que lo fue no ha ocho días y lo dejó de ser inadvertida y loca y por creerse de palabras compuestas 
y afeitadas de fementidos hombres" (CERVANTES, p. 150). Frente à sua própria desonra, vemos que é a mulher mesma quem se coloca como "inadvertida" e "loca".

O longo diálogo travado entre os irmãos exemplifica o respeito às regras ditadas na educação de ambos os filhos, o que a faz legitimar os sentimentos expostos.

Mis padres [...] tuvieron un hijo y una hija: él para descanso y honra suya, y ella para todo lo contrario. A él enviaron a estudiar a Salamanca. A mí me tenían en su casa, adonde me criaban con el recogimiento y recato que su virtud y nobleza pedían; y yo, sin pesadumbre alguna, siempre les fui obediente, ajustando mi voluntad a la suya sin discrepar un solo punto. (CERVANTES, p. 150).

Da história para a ficção

Como dizia Antonio de Guevara (1964), o homem precisava ser "bem criado", de acordo com as virtudes da sabedoria, decência e discrição. Segundo rezavam os códigos morais e religiosos, a educação de homens e de mulheres merecia alguma distinção. Para Vives (1995), as mulheres deveriam ser educadas também nas letras, embora com algumas restrições de leituras, pois ele mesmo ressalta que "veo algunos tener por sospechas a las mujeres que saben letras, pareciéndoles que es echar aceite en el fuego dándoles a ellas avisos y añadiendo sagacidad a la malicia natural que algunas tienen" (VIVES, 1995, p. 49). A precisão da fala da protagonista há pouco registrada deixa bem clara a distinção de tratamento dada à educação de homens e de mulheres, além de denotar o compromisso da sua família nobre com aquela educação dentro dos parâmetros estabelecidos, pois, como observa Jean Delumeau, "[o]s rapazes das classes desafogadas encaminhavam-se, cada vez mais, para os colégios; mas as raparigas, em geral, permaneciam em casa" (DELUMEAU, 1984, p. 88). Ainda assim, empenha-se em demonstrar a sua boa educação e, ao mesmo tempo, exprime que sua ação se deve a ter "faltado la memoria en parte donde tanto me importaba tenerla" (CERVANTES, 1995, p. 149). O esclarecimento parece certificar a "malicia natural" e o "receio das vulnerabilidades" tanto repisados pelos filósofos e moralistas desde a Antiguidade até os tempos da enunciação.

É a mesma protagonista que entende o seu "tra"vestir-se como uma forma de transgressão, de punição à conduta que derrubava parte 
da fortaleza de sua honra. Pelas suas palavras em longa lamentação, exposta no fragmento a seguir:

Castigué mis cabellos, como si ellos tuvieran la culpa de mi yerro; martiricé mi rostro, por parecerme que él había dado toda la ocasión a mi desventura; maldije mi suerte, acusé mi presta determinación, derramé muchas e infinitas lágrimas, vime casi ahogada entre ellas y entre los suspiros que de mi lastimado pecho salían [...]. (CERVANTES, p. 151).

Edwirgens A.

Ribeiro Lopes

Todos os seus comportamentos são decorrentes do seu ser mude Almeida lher e de estar sintonizada com a ordem imposta sobre os gêneros. Vemos que toda a narrativa é construída sobre a sua personalidade de mulher coerente com o contexto de seu entorno. Ao tomar conhecimento de que o seu interlocutor é seu irmão Don Rafael, mais uma vez, ciente das práticas e ideias proeminentes naquele tempo, Teodosia pede que lhe tire a vida, dizendo, entre outras palavras, "[y]o confieso mis pecados y no quiero que me sirva de desculpa mi arrepentimiento; sólo te suplico que la pena sea de suerte que se extiende a quitarme la vida y no la honra" (CERVANTES, p. 155), e em seguida manifesta a sujeição "[s]u hermana le dijo que hiciese todo aquello que mejor le pareciese, porque ella no tenía más voluntad que la suya" (CERVANTES, p. 157). Sabendo a personagem que, no âmbito histórico, a desonra constituída de uma donzela se tornava um problema dos demais familiares, cabia aos pais e aos irmãos cobrar-lhe a honra perdida em nome do bem-estar da família. Como a mulher era a responsável por guardar sua própria honra para não pôr em risco a dos outros da mesma casa, podemos observar que a personagem mostra-se passiva ao conviver com as regras sociais. Assegura Defourneaux que a honra é conquistada por meio das virtudes e que fica o sujeito passível de perdê-la por meio da conduta dos outros. "A honra que se constitui em louvor, reverência ou consideração que o homem ganha por sua virtude ou boas obras é ainda expressão do valor individual, é também um valor social que cada qual se expõe a perder por via de outrem." (DEFOURNEAUX, 1983, p. 42-43).

Tendo em conta que a honra, sobretudo da mulher, era imprescindível também naquele cenário ficcional, temos, no mesmo intuito da protagonista, a personagem Leocadia. Esta foi encontrada pelos dois irmãos e amarrada em uma árvore por bandoleiros. Vestida de homem e se apresentando pelo nome de Francisco, Teodosia, travestida de 
Teodoro, logo percebe naquele varão alguns traços femininos e, pouco a pouco, vai confirmando as suas suspeitas. Teodosia observa atentamente os gestos e o corpo daquele mancebo, que "le pareció que tenía las orejas horadas; y en esto y un mirar vergonzoso que tenía sospechó que debía de ser mujer" (CERVANTES, p. 160). Teodosia logo oferece a sua ajuda e promete que guardará tudo em segredo. Explica o narrador:

Con grande atención estaba el mancebo escuchando la que Teodoro le decía. Y viendo que ya callaba, antes que le respondiese palabra, le tomó las manos y, llegándoselas a la boca, se las besó por fuerza, y aun se las bañó con gran cantidad de lágrimas que de sus hermosos ojos derramaba, cuyo extraño sentimiento le causó en Teodoro de manera que no pudo dejar de acompañarle en ellas (propia y natural condición de

Da história para a ficção mujeres principales enternecerse de los sentimientos y trabajos ajenos). (CERVANTES, p. 162).

Nesse trecho, apenas os trajes de ambas são argumentos suficientes para esse narrador designá-las como homens. São destacados o choro de Leocadia, na condição de Francisco, que causa estranhos sentimentos em Teodoro. Parece contraditório chamá-lo assim, já que é explicado que Teodoro também chora, mas, em seguida, argumenta e põe em destaque, entre parênteses, que essa condição é própria das mulheres, "propia y natural condición de mujeres principales enternecerse de los sentimientos y trabajos ajenos" (CERVANTES, p. 162). Nesse momento, a manifestação dessa sensibilidade, própria da mulher, na visão do narrador, é um elemento que aproxima as duas moças, que se vestem de homens. Ao explicar o motivo daquela transformação, Leocadia ilustra aquele sentimento de modo mais objetivo que Teodosia, porém não com menos lamentações. Fazendo as descrições do mesmo varão Marco Antonio, objeto da desventura de Teodosia, Leocadia esclarece que, naquela ocasião,

tomó la fortuna, o el amor, o mi poca advertencia, la que fue bastante para derribarme de la alteza de mis buenos pensamientos a la bajeza del estado en que me veo; pues habiendo mirado, más de aquello que fuera lícito a una recatada doncella, la gentileza y discreción de Marco Antonio y considerado la calidad de su linaje y la mucha cantidad de los bienes que llaman de fortuna que su padre tenía, me pareció que, si le 
alcanzaba por esposo, era toda la felicidad que podía caber en mi deseo (CERVANTES, p. 164).

O trecho ficcional em questão põe em destaque a prática desse período observada pelo historiador Defourneaux (1984) de que o melhor destino das mulheres nobres era o casamento. Esperava-se encontrar um marido com boas condições econômicas, a quem o pai pudesse passar a responsabilidade pelo controle feminino. Leocadia então, venEdwirgens A. do em Marco Antonio tais predicativos para um bom provedor, contiRibeiro Lopes nua seu esclarecimento:

de Almeida

con este pensamiento le comencé a mirar con más cuidado, y debió de ser sin duda con más descuido, pues él vino a caer en que yo le miraba, y no quiso ni le fue menester al traidor otra entrada para entrarse en el secreto de mi pecho y robarme las mejores prendas de mi alma (CERVANTES, p. 164).

Com sua entrega, a personagem permite ao sedutor ferir aquilo que, sob o discurso religioso, a mulher tinha de mais precioso: sua honra manifestada na castidade.

No fragmento citado, de maneira dissemelhante ao que lamentou Teodosia, Leocadia exibe dúvida das razões que a levaram a tentar um encontro com Marco Antonio. O que mais claro ficou nesse enunciado é que ela encontrava naquele rapaz alguns predicativos ideais para um marido. Por trás desse desejo do casamento, está a ação feminina de perseguir o seu intento, já que era uma prática predominante o casamento arranjado pelos pais. Como explica Alfonso de Valdés no “Segundo Livro", do Diálogo de Mercúrio e Caronte,

como não é lícito e honesto às mulheres escolherem o marido que elas querem mas parecem ser obrigadas a tomar o que seus pais, irmão ou parentes querem dar-lhes, ainda que eu, não poucas vezes, rogasse que não olhassem linhagem, nem bens mundanos, nem formosura do corpo, senão as virtudes da alma (VALDÉS, 1964, p. 186).

A voz da Alma expressa nesse diálogo revela que a atitude tomada por ambas as mulheres ficcionais pode ser considerada uma subversão. 
O diálogo elucida que "não é lícito", isto é, a independência da mulher frente à escolha do esposo era considerada um gesto transgressivo, já que essa escolha cabia aos pais, irmãos ou parentes. No caso de Leocadia, temos ainda um gesto autônomo quando ela explica as razões por que escolheu Marco Antonio como pretendente a marido, destacando a gentileza e a discrição, embora aparentemente privilegie a sua linhagem, os bens do pai daquele varão. Reitera Mariló Vigil que

\footnotetext{
una joven de clase media o alta del siglo XVI debía estar sometida a sus padres y seguir en todo momento sus dictados, con objeto de no dificultar su matrimonio. Casarse era para ella vital; como no tenía más posición que la familiar, no recibía otra educación que la precisa para integrarse en el seno de la familia (VIGIL, 1994, p. 89).
}

Da história para a ficção

Juan Luis Vives foi uma das vozes a recusar a norma de que as donzelas pudessem intervir na eleição do marido. Para ele, o que elas podiam fazer era "con votos e orações suplicando con grand aflicción y lágrimas a nuestro Señor, que alumbre e inspire el corazón de sus padres (VIVES, 1995, p. 40). Dessa forma, temos mulheres flexibilizando certo prescrito para elas, agindo em um ambiente dominado pelo poder masculino. Contraditoriamente, essas mulheres subvertem, de algum modo, a prática em vigor quando se vestem de homens para alcançar o espaço público; o que elas procuram, de fato, é, ironicamente, manter a tradição.

Teodosia, com muito ciúme ao ouvir falar do possível envolvimento da outra com o homem amado, logo questiona se haviam consumado a relação. Depois da negação, Leocadia explica que teve conhecimento de que Marco Antonio havia fugido com Teodosia, a quem qualifica como "doncella de extrema hermosura y de rara discreción [...] más hermosa que el sol y más discreta que la discreción misma, y sobre todo, más venturosa que yo, sin ventura" (CERVANTES, p. 165). Consoante o que explicamos anteriormente, a caracterização das mulheres quanto à sua beleza é sempre hiperbólica nesses contos de que estamos tratando. Aqui é uma mulher quem elogia a outra, embora as duas estejam vestidas de varões. Nesse excerto, ainda fica entrevista a superioridade de uma sobre a outra, o que, conforme Linda Britt (1988), vai determinar a preferência de Cervantes pela heroína ideal. Vale lembrar, 


\section{Edwirgens A.}

Ribeiro Lopes

de Almeida porém, que, nos tempos da enunciação cervantina, pelo postulado de Guevara (1964), a beleza do corpo se relacionava à beleza da alma, o que nos faz, de certo modo, compreender a escolha do autor.

Enquanto Teodosia segue a sua trajetória ao lado de Leocadia com muitos ciúmes, mas procurando dissuadi-la da sua culpa, já que esta última não sabe que Teodoro e Teodosia são a mesma pessoa, Leocadia persiste no seu intento de vingança. Assim, avisa, "ella le goza, sin duda, sea donde fuere; y ella sola ha de pagar lo que he sentido hasta que le halle" (CERVANTES, p. 167). Por essa advertência da personagem, podemos depreender que, com vistas nas informações de Vives e de Guevara, Leocadia, com essa atitude, apresenta menos atos de nobreza que a rival Teodosia. Ainda sobre a mesma questão, enfaticamente, declara:

[m]as el dolor que siento de los celos me la representa en la memoria bien así como espada que atravesada tengo por mitad de las entrañas, y nos mucho que, como a instrumento que tanto me lastima, le procure arrancar dellas y hacerle pedazos; cuanto más, que prudencia es apartar de nosotros las cosas que nos dañan, y es natural cosa aborrecer lo que nos hacen mal y aquellas que nos estorban el bien (CERVANTES, p. 168).

Se essa personagem busca um final para si ao lado do que acredita ser o homem ideal, as suas atitudes contrastam com esse perfil de mulher abúlica, passiva, subserviente. Mesmo as duas se travestindo a fim de alcançar o espaço público, a atuação de cada uma delas é bem diferente. Enquanto Teodosia procura ser sensível, prudente e, por vezes, cativa de sua situação, Leocadia se mostra ativa, vingativa, decidida e ressentida. Esta última engendra mais ações que a primeira. Sendo assim, exibe uma atuação um tanto mais coerente com o desempenho de um homem, isto é, ela assume um pouco mais que Teodosia aquela transformação.

Ainda que o disfarce possa ser entendido como uma ousadia, essas mulheres mantêm o receio diante do seu lugar na sociedade, como pode ser entrevisto na argumentação de Leocadia quando autoriza Teodosia a revelar a sua identidade a Don Rafael, porém "suplicándole que no la desamparase, pues veía a cuántos peligros estaba puesta si por mujer fuese conocida" (CERVANTES, p. 168). Embora atenta aos perigos que enfrentaria socialmente na identidade de mulher, Leocadia, 
novamente, veste-se de mulher, mas também assim continua sua busca por Marco Antonio ao lado de Teodosia, ainda vestida de homem, e Don Rafael. Os novos trajes de Leocadia e o conhecimento de sua origem nobre despertam um forte sentimento em Don Rafael, ao mesmo tempo que aumentam os ciúmes de Teodosia.

Embora procure uma união com a ordem predominante através do casamento, Leocadia exibe, no desfecho da história, as mesmas razões que foram apresentadas a fim de justificar a sua busca por Marco Antonio, "mas sea como fuere, que en fin, el nombre de ser mujer legítima de don Rafael de Villavicencio no se podía perder, y con este título solo viviré contenta" (CERVANTES, p. 183). Se por um lado as ambições dessas mulheres se resumem ao casamento, Leocadia ratifica aquela sua atuação, isto é, não se prendendo aos sentimentos, procura um preten-

Da história para a ficção dente que lhe dê um "título". o termo expressa bem o sentido do casamento para algumas mulheres e, aparentemente, ajusta-se ao interesse de Leocadia; sem a demonstração de muitos sentimentos, busca o reconhecimento das pessoas para a sua condição de mulher. Pondera Mariló Vigil: "la voz de Cervantes fue una de las que se levantó contra aquellos matrimonios decididos al margen de la voluntad de la desposada [...] y defiende la norma de su sociedad de que los matrimonios se celebren entre personas de la misma posición" (VIGIL, 1994, p. 82).

Tendo em vista as ponderações acerca da atuação feminina nessa obra, e a possível crítica cervantina feita sobre a situação da mulher, sobretudo em se tratando da busca do casamento, convém partilhar com Walter Pabst que

el escritor no piensa, en modo alguno, que se trate de mujeres sin voluntad propia ni derecho de autodeterminación; en las ‘seducidas' nos demuestra justamente lo contrario. En efecto, estas mujeres han sido atraídas por influencias extrañas al camino de la pasión, pero han caído en culpa por su propia y libre disposición de voluntad (PABST, 1972, p. 233).

A interpretação de Pabst comunga da leitura que vimos empreendendo sobre Las dos doncellas, isto é, a narrativa, a seu modo, vai demonstrando como as mulheres atuam, seja por meio de suas forças, seja de suas fragilidades. Para exemplificar a "libre disposición de la voluntad" (PABST, 1972, p. 233), convém rememorar que Teodosia procura 
Edwirgens A.

Ribeiro Lopes

de Almeida atribuir a culpa de seus maus atos a Marco Antonio, alegando as artes da sedução. Entretanto, no final do relato de sua história, é interpelada pelo irmão, “conforme a esto os debió de engañar más vuestra voluntad rendida que las persuasiones de Marco Antonio, todavia quiero tomar por desculpa de vuestro yerro vuestros pocos años" (CERVANTES, p. 153). Ainda, ela mesma reconhece, em suas lamentações, “Adónde me lleva la fuerza incontrastable de mis hados? [...] Ay pocos y mal experimentados anõs, incapaces de toda buena consideración y consejos!" (CERVANTES, p. 147). No fragmento, a protagonista reconhece o mau passo como fruto de seus próprios atos, motivados pela inexperiência dos poucos anos.

Ao exigir os seus direitos frente ao sedutor, Leocadia escuta de 218 Marco Antonio: "confieso, hermosa Leocadia, que os quise bien y que me quisestes, y juntamente con esto confieso que la cédula que os hice fue más por cumplir con vuestro deseo que con el mío" (CERVANTES, p. 178). Com esse esclarecimento, o sedutor evidencia que, por iniciativa da mulher, é que ele lhe deu a cédula, visando ao cumprimento de um desejo dela. É pertinente observar que, diante da dinâmica passiva ou ativa da mulher, no momento em que chegam a Barcelona, Teodosia, Leocadia e Don Rafael encontram um grupo de pessoas em uma briga, e logo as duas identificam que um daqueles homens era Marco Antonio. A ação de ambas é imediata em favor do homem desejado.

Y en diciendo esto, con gran ligereza saltaron de las mulas, y poniendo mano a sus dagas y espadas, sin temor alguno se entraron por mitad de la turba y se pusieron la una a un lado y la otra al otro de Marco Antonio [...]. (CERVANTES, p. 173).

Mais uma vez, dentro do cenário ficcional, vemos as mulheres agindo, neste caso, em favor do homem, a pretexto do amor, mas procurando a realização de si mesmas. Também levantam a voz para acalmar o ânimo do cavaleiro. Diz Leocadia: "No temáis, señor Marco Antonio, que a vuestro lado tenéis quien os hará escudo con su propia vida por defender la vuestra", e ressalta Teodosia, vestida de Teodoro, "Quién lo duda, estando yo aquí?" (CERVANTES, p. 173). A valentia e a bravura das personagens aqui entrevistas contrastam com a atuação delas mesmas quando pretendem o casamento ao molde convencional e revelam o quanto era dinâmica a sociedade vista no papel. o procedimento delas 
é atestado pelo próprio narrador, que comenta: "se iban retirando a sus lados las dos valientes y nuevas Bradamante y Marfisa o Hipólita y Pantasilea" (CERVANTES, p. 173). $\mathrm{O}$ adjetivo "valente" é adequado para caracterizar essas duas mulheres personagens em suas ações, já que estão todas elas no plano do imaginário e, como explica Rosa Navarro Durán (1995), elas são mulheres guerreiras, sendo Brandamante e Marfisa personagens de Orlando innamorato, de Boiardo, e de Orlando furioso, de Ariosto. Pela mitologia grega, Hipólita e Pentesilea foram rainhas das Amazonas, uma nação formada por mulheres guerreiras. Sendo irmãs, eram simbolizadas na arte clássica lutando contra guerreiros gregos.

Conforme explicamos no princípio deste texto, é importante rememorar a história das mulheres, seja no aspecto histórico, seja ficcional, uma vez que o percurso delineado por elas serviu de comparação

Da história para a ficção

\section{Referências}

BRITT, Linda. Teodosia's dark shadow? A study of women's roles in Cervantes's Las dos doncellas. Cervantes: Bulletin of the Cervantes Society of America, v. 8.1, p. 39-46, 1988. Disponível em: <http:// www.h-net.org/ cervant/csa/artics88/britt.htm>. Acesso em: 19 fev. 2013.

CERVANTES, Miguel de. Las dos doncellas. In: Novelas ejemplares. Edición, introducción y notas de Rosa Navarro Durán. Madrid: Alianza Editorial, 1995. v. 2, p. 143-189. 
DEFOURNEAUX, Marcelin. A vida quotidiana em Espanha no século de ouro. Trad. de André Carga. Lisboa: Livros do Brasil, 1984.

DELUMEAU, Jean. A civilização do Renascimento. Trad. de Manuel Ruas. Lisboa: Editorial Estampa, 1983. v. 1.

GUEVARA, Antonio de. Epístolas familiares. In: PÉREZ, David J. (Seleção e prefácio). Moralistas espanhóis. Trad. de Acácio França. Edwirgens A. São Paulo: Brasileira, 1964. p. 191-275. (Clássicos Jackson, v. 11).

Ribeiro Lopes de Almeida

LEÓN, Fray Luis. La perfecta casada. Madrid: Aguilar, S.A. de Ediciones, 1953.

LIMA, Luiz Costa. A problemática dos livros de ficção entre os espanhóis do século XVI. In: Trilogia do controle. 3 . ed. Rio de Janeiro: Topbooks, 2007. p. 247-258.

NAVARRO DURÁN, Rosa. Edición, introducción y notas. In: CERVANTES, Miguel de. Novelas ejemplares. Madrid: Alianza Editorial, 1995. Vol. 1 e 2 .

PABST, Walter. La novela corta en la teoria y en la creación literaria. (Versión española de Rafael de la Vega) Madrid: Editorial Gredos, 1972.

PIZÁN, Cristina de. La ciudad de las damas. Edición a cargo de Marie-José Lemarchand. 2. ed. Madrid: Ediciones Siruela, 2001.

SOUILLER, Didier. La novela picaresca. Trad. de Beatriz PilladoSalas. México: Fondo de Cultura Económica. 1985.

RILEY, Edward C. Teoria de la novela en Cervantes. (Versión castellana de Carlos Sahagún) Madrid: Taurus, 1981.

VALDÉS, Alfonso de. Diálogo de Mercúrio e Caronte. In: PÉREZ, David J. (Seleção e prefácio). Moralistas espanhóis. Trad. de Acácio França. São Paulo: Brasileira, 1964. p. 105-189. (Clássicos Jackson, v. 11). 
VIGIL, Mariló. La vida de las mujeres en los siglos XVI y XVII. 2 ed. Madrid: Siglo XXI de España Editores, 1994.

VIVES, Juan Luis. Instrucción de la mujer cristiana. Trad. de Juan Justiniano. Madrid: Fundación Universitaria Española, Universidad Pontificia de Salamanca, 1995.

Da história para a ficção 
